\title{
A bibliometric analysis of research on haze during 2000-2016
}

\author{
Chenxi $\mathrm{Li}^{1}{ }^{1} \cdot$ Kening $\mathrm{Wu}^{1,2} \cdot$ Jingyao $\mathrm{Wu}^{1}$
}

Received: 18 July 2017 / Accepted: 5 October 2017 / Published online: 15 October 2017

(C) Springer-Verlag GmbH Germany 2017

\begin{abstract}
As one of the bibliometric analysis tools, CiteSpace software was applied to quantitatively and visually evaluate global scientific documents of research on haze from 2000 to 2016. Five thousand six hundred six documents from the Science Citation Index Expanded (SCI-Expanded) and Social Science Citation Index (SSCI) of the Web of Science database were statistically analyzed and examined. The distributions on authorship, countries/territories, institutes, and keywords were generated. The amount of publications has increased nearly for the past 17 years. The most productive author was Li J. with 46 articles. The publications on haze research were primarily originated from the USA, China, Germany, and France. By synthetically analyzing the keywords, the dominant hot spots of haze research could be concluded as "aerosol," "atmosphere," "particle," " $\mathrm{PM}_{2.5}$," and "air quality."
\end{abstract}

Keywords Bibliometric analysis $\cdot$ Haze $\cdot$ Web of Science CiteSpace

Responsible editor: Philippe Garrigues

Chenxi Li

xywglcx@163.com

Kening Wu

wukening@cugb.edu.cn

Jingyao $\mathrm{Wu}$

1120773302@qq.com

1 School of Land Science and Technology, China University of Geosciences (Beijing), Beijing 100083, China

2 Key Laboratory of Land Consolidation, Ministry of Land and Resources, Beijing 100035, China

\section{Introduction}

Haze, which is produced by smoke, fog, dust, and other tiny particles in the air, often occurs in the metropolis (Kim Oanh and Leelasakultum 2011; Yang et al. 2015). Haze is mainly composed of $\mathrm{PM}_{10}$ and $\mathrm{PM}_{2.5}$. Haze weather can not only reduce visibility, increase the frequency of traffic accidents, but also cause decline in air quality and induce respiratory and cardiovascular diseases (Hand et al. 2014; Zhang et al. 2015c; $\mathrm{Fu}$ and Chen 2017); The haze phenomenon can also have an impact on the earth's climate effect by affecting the earth's radiation budget situation (Davies and Unam 1999; Bytnerowicz et al. 2003; Tonnesen et al. 2003). Therefore, haze problem has attracted more and more attention.

Some scholars have analyzed the solutions of controlling haze weather (Gao 2008; Voiland 2010; Wang and Zheng 2013). Fu and Chen (2017) proposed the suggestions on future directions of haze pollutions in China by reviewing factors contributing to haze formation. Kulmala (2015) considered that the air pollution control remains a great challenge because urban air is a complex cocktail of chemicals whose poorly understood interactions and feedbacks may exacerbate health problems; Many researchers have examined the components of $\mathrm{PM}_{2.5}$ from the chemical and physical properties (Bates and Sizto 1987; Thurston et al. 1994; Ma et al. 2012; Jansen et al. 2014; Sun et al. 2015; Zhang et al. 2015b; Wu et al. 2017); There also have been many published papers which have revealed the characteristics of haze problem from the human health perspective (Davis et al. 2002; Tie et al. 2009; Liu et al. 2015; Ren et al. 2016).

As a statistical and visible approach on published papers, bibliometrics provides a way to analyze academic documents quantitatively (Mayr and Scharnhorst 2014; Chen et al. 2016). There have been a lot of studies which evaluate research relationships of authors, institutes, countries, etc. in specific 
research fields (Wang et al. 2010; Abramo, et al. 2011; Gupta and Bala 2012; Matthews 2013; Bajwa and Yaldram 2013; Li and Zhao 2015). In recent years, a great number of publications have been published on haze and related fields. There have been 5606 documents on haze in the Science Citation Index Expanded (SCI-Expanded) and Social Science Citation Index (SSCI) of the ISI-Thomson Reuters Scientific database from 2000 to 2016. Much attention has been paid to haze problem; however, few papers attempted to analyze and examine global academic publications data visually. Therefore, the present study is to reveal research patterns in the characteristics of author distribution, international collaboration, and academic relationship on haze research.

\section{Methodology and data collection}

\section{Methodology}

Bibliometric methods provide an approach to identify the development trends or future research orientations by analyzing the publication output, keywords, authors, institutes, countries ( $\mathrm{Li}$ et al. 2015; Chen et al. 2016). The statistical results related to distribution of authors, institutes, countries/territories, and keywords can be visually showed by using bibliometric analysis tools including VOSviewer, Citespace, and HistCite.

CiteSpace is a scientific visualization software which is used for visualizing and mapping statistical publication data from the ISI-Thomson Reuters Scientific database. It is a freely available Java application for visualizing and analyzing trends and patterns in scientific literature. It focuses on finding pivotal points in the evolution of a research field. Providing various functions to facilitate the understanding and interpretation of network patterns, CiteSpace can identify the fast-growth topical areas; find citation hotspots in the assemblage of publications; and decompose a network into clusters, automatic label clusters with terms from citing articles, geospatial patterns of collaboration, and unique areas of international collaboration (Chen 2014). CiteSpace not only supports structural and temporal analyses of a variety of networks derived from scientific publications, including collaboration networks, author co-citation networks, and document co-citation networks, but also supports networks of hybrid node types such as terms, institutes, and countries, and hybrid link types such as cocitation, co-occurrence, and directed citing links (Chen 2004). The primary source of input data for CiteSpace is the Web of Science. CiteSpace will handle the data from there. Besides, CiteSpace can be used to generate geographic map overlays viewable in Google Earth based on the locations of authors (Chen 2006).

\section{Dataset for visualization analysis}

The data for the present study were collected in March 2016 from Web of Science (http://webofknowledge.com). In particular, the Science Citation Index Expanded (20002016), Social Science Citation Index (SSCI, 2000-2016), have been collected through the online documents published by Thomson Reuters. The data retrieval strategies were set as follows:

Topic = "Haze"; it means that the word in title, abstracts or keywords of articles will be retrieved.

Timespan $=2000-2016$.

Five thousand six hundred six papers were collected in this study.

\section{Parameter design}

Time Slicing was set from 2000 to 2016. Years Per Slice was set 1. Term Source was set "Title," "Abstract," "Author Keyords (DE)," "Keywords Plus (ID)." Term Type was set "Burst Terms." Node Types were set "Author," "Institution," "Country," and "Keyword," respectively. The size of circles represents the publication number, and the distance between two circles is inversely proportional to the collaboration between two authors, countries/territories, and institutes. Concretely, the shorter distance between two circles is, the more collaboration between two authors is.

The overall methodology is shown in Fig. 1.

\section{Results and discussion}

\section{Publication year}

From the period of 2000 to 2016, 5606 documents were published in the ISI-Thomson Reuters Scientific database. In 2000, 153 documents were published; the number of documents increased as 779 was in 2016. Yearly research outputs are shown in Fig. 2. Results revealed that the research on haze was nearly consistently the focus of scholars during the past 17 years.

Most areas in China have forecasted haze weather as a kind of severe weather warning since 2011 (Zhang et al. 2015d; Gao et al. 2017). Owing to high levels of atmospheric pollutant emissions, more serious haze episodes occurs in China after 2013, especially in urban agglomerations such as the Beijing-Tianjin-Hebei region, the Yangtze River Delta area, and the Pearl River Delta area (Fu and Chen 2017; Li et al. 2017). In response to the extremely serious haze pollution, the Chinese State Council decided to reduce and control concentrations of 


\begin{tabular}{|c|c|c|c|}
\hline $\begin{array}{l}\text { Data retrieved } \\
\text { Web of Science }\end{array}$ & Data analysis & Findings & Results \\
\hline $\begin{array}{l}\text { Publication Type } \\
\text { Authors } \\
\text { Affiliations } \\
\text { Title } \\
\text { Source } \\
\text { Language } \\
\text { Document type } \\
\text { Abstract } \\
\text { Cited Reference }\end{array}$ & $\begin{array}{l}\text { Excel: } \\
\text { - Basic statistic for the data } \\
\text { CiteSpace: } \\
\text { - Author co-citation } \\
\text { map } \\
\text { - Country/territory co- } \\
\text { citation map } \\
\text { - Institute co-citation } \\
\text { map } \\
\text { - Time zone view of the } \\
\text { keywords co-citation } \\
\text { map } \\
\text { Google Map: } \\
\text { - Geographical map of } \\
\text { countries/territory co- } \\
\text { citation }\end{array}$ & \begin{tabular}{|l} 
Distribution of haze \\
research \\
- Publications trend \\
- International \\
collaboration \\
(including authors, \\
countries/territories, \\
institutes and \\
keywords) \\
- Academic relationship \\
(including authors, \\
countries/territories, \\
institutes and \\
keywords)
\end{tabular} & $\begin{array}{l}\text { Trend of haze } \\
\text { research } \\
\text { - Authors } \\
\text { - Countries/territories } \\
\text { - Institutes } \\
\text { Hotspot and main } \\
\text { research area } \\
\text { of haze }\end{array}$ \\
\hline
\end{tabular}

Fig. 1 Research methodology

$\mathrm{PM}_{2.5}$ (Wang et al. 2014; Zhang et al. 2015a). To achieve the goal, the Chinese government proposed 10 prevention measures for aerosol pollution control called Atmospheric Pollution Prevention and Control of the Ten Measures of China (http://www.gov.cn/gzdt/2013-09/16/content_ 2489162.htm). Those have obtained continuous attention among scholars to reduce emissions caused by aerosols with an emphasis on fossil fuel combustion, vehicle exhaust, and industrial waste gas (Guo et al. 2014; Zhang et al. 2015c). All of those may explain the reason why the publications related to haze began to have a high growth rate from 2013.

\section{Authorship}

The academic cooperative connections among authors generating research on haze were shown in Fig. 3. Tended to cooperate with small groups of collaborators, the authors generated several clusters. The top 30 most productive authors for total publications are shown in Table 1 . The major academic
Fig. 2 Annual publication related to haze in the WOS core collection, published from 2000 to 2016

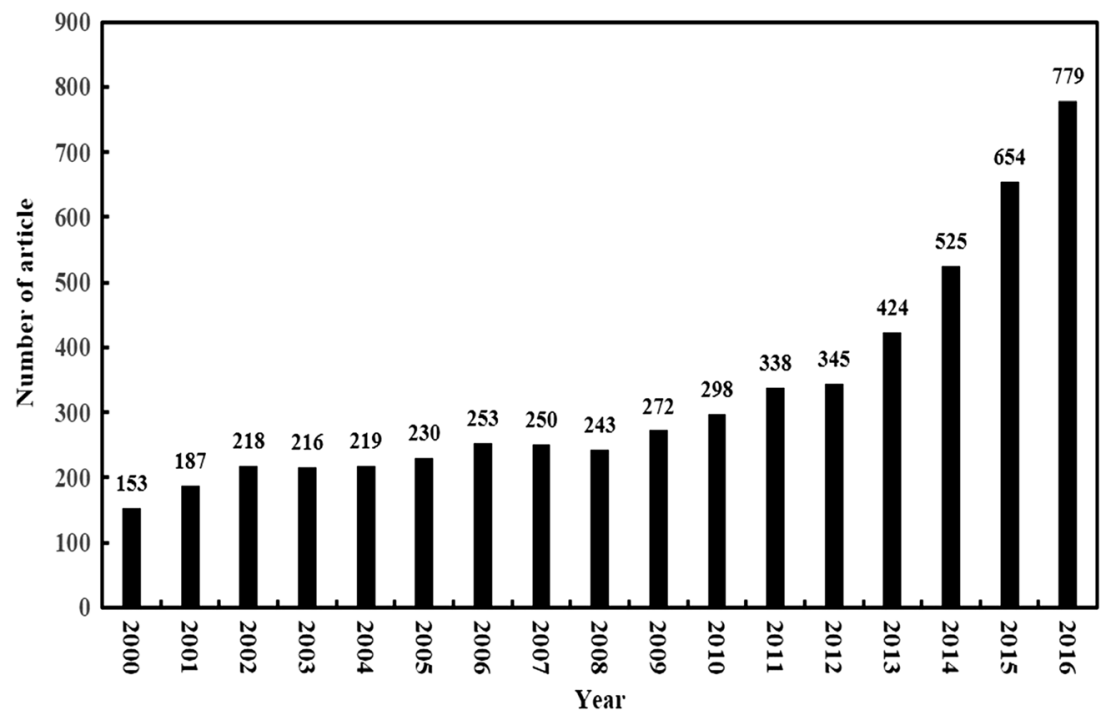




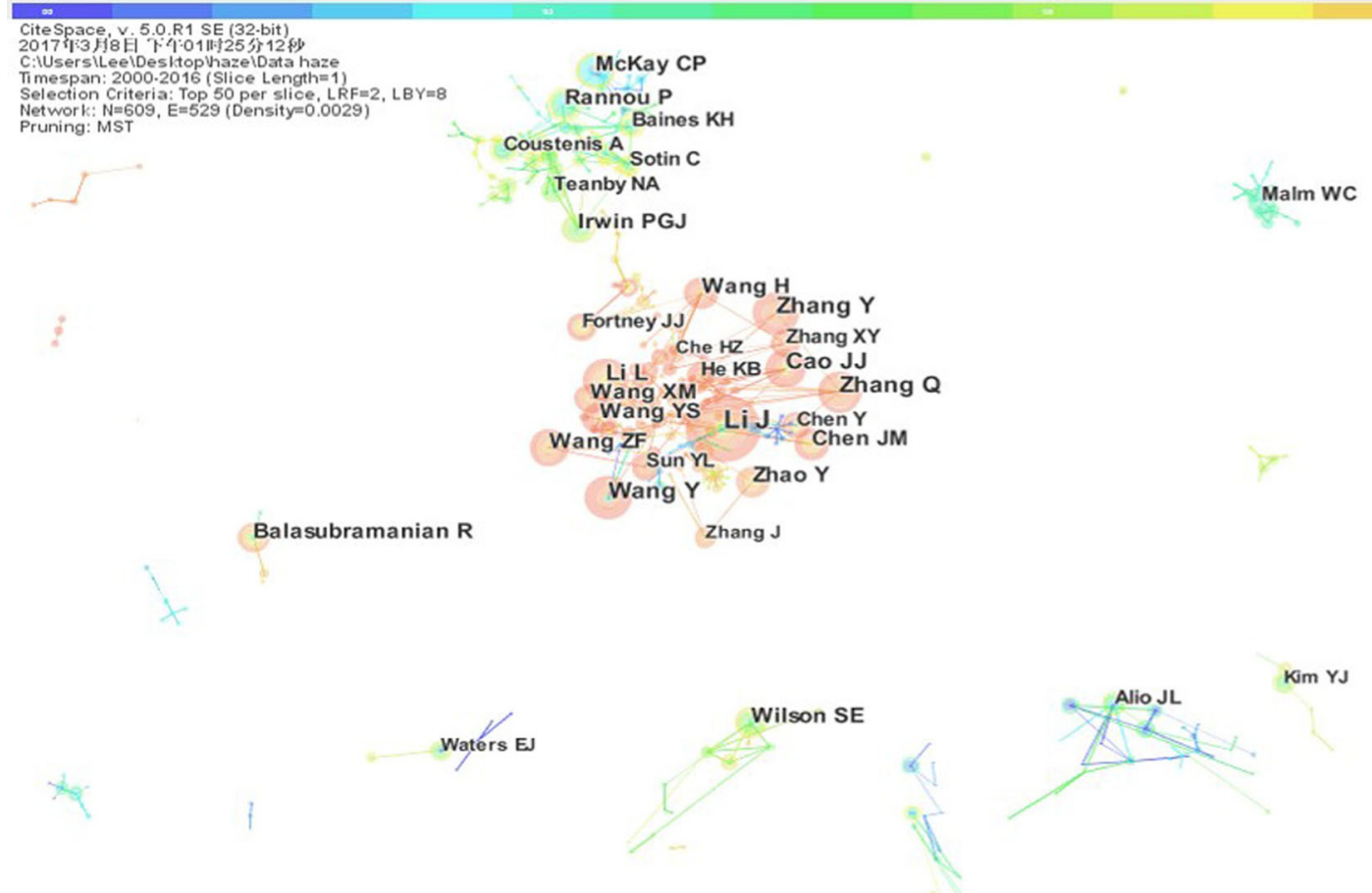

Fig. 3 Author co-citation map from 2000 to 2016

contributions, which were concluded in terms of total publication frequency, primarily originated from Li J., Li L., Zhang Y. and Wang Y. As to the publication distribution of the top 30 most productive authors, 46 from Li J., followed by 29 from Li L, 29 from Zhang Y., 29 from Wang Y., 27 from Zhang Q., 26 from Cao J.J., 25 from Wang Z.F., 25 from McKay C.P., 22 from Rannou P., 21 from Wang Y.S., 21 from Wilson S.E., 21 from Chen J.M., 21 from Zhao Y., 21 from Wang H., 21 from Irwin P.G.J., 20 from Wang X.M., 20 from Balasubramanian R., 19 from Fortney J.J., 18 from Malm W.C., 18 from Chen Y., 18 from Zhang X.Y., 18 from Sun Y.L., 18 from He K.B., 17 from Coustenis A., 17 from Alio J.L., 17 from Baines K.H., 16 from Teanby N.A., 15 from Sotin C., 14 from Che H.Z., and 14 from Waters E.J.

Table 1 The top 30 most productive authors

\begin{tabular}{llllll}
\hline Number & Frequency & Author & Number & Frequency & Author \\
\hline 1 & 46 & Li J. & 16 & 20 & Wang X.M. \\
2 & 29 & Li L. & 17 & 20 & Balasubramanian R. \\
3 & 29 & Zhang Y. & 18 & Fortney J.J. \\
4 & 29 & Wang Y. & 19 & 19 & Malm W.C. \\
5 & 27 & Zhang Q. & 20 & 18 & Chen Y. \\
6 & 26 & Cao J.J. & 21 & 18 & Zhang X.Y. \\
7 & 25 & Wang Z.F. & 22 & 18 & Sun Y.L. \\
8 & 25 & McKay C.P. & 23 & 18 & He K.B. \\
9 & 22 & Rannou P. & 24 & 17 & Coustenis A. \\
10 & 21 & Wang Y.S. & 25 & 17 & Alio J.L. \\
11 & 21 & Wilson S.E. & 26 & 17 & Baines K.H. \\
12 & 21 & Chen J.M. & 27 & 17 & Teanby N.A. \\
13 & 21 & Zhao Y. & 28 & 14 & Sotin C. \\
14 & 21 & Wang H. & 29 & 14 & Che H.Z. \\
15 & 21 & Irwin P.G.J. & 30 & Waters E.J. \\
\hline
\end{tabular}




\section{Countries/territories}

To map the distribution of publications on haze, we obtained a network based on the author's countries/territories by using CiteSpace. A network was displayed that including nodes and links representing the collaborations among countries/territories. Geographical map can be generated using Generate Google Earth Maps (KML 2.0) in CiteSpace after gaining the countries/territories co-citation results.

The academic cooperative connections among countries/ territories generating research on haze were shown in Fig. 4a. The top 30 most productive countries/territories for total publications are shown in Table 2. The major academic contributions, which were concluded in terms of total publication frequency, primarily originated from the USA, China, Germany, and France. As to the publication distribution of the top 30 most productive countries/territories, 1925 are from the USA, followed by 1162 from China, 432 from Germany, 425 from France, 323 from England, 297 from South Korea, 268 from Italy, 259 from Japan, 223 from Canada, 197 from Spain, 179 from India, 162 from Australia, 158 from Taiwan, 114 from Netherlands, 108 from Switzerland, 95 from Singapore, 83 from Brazil, 68 from Turkey, 67 from Sweden, 63 from Malaysia, 62 from Norway, 61 from Russia, 59 from Belgium, 52 from Finland, 52 from Denmark, 49 from Greece, 45 from Israel, 43 from Austria, 43 from Portugal, and 38 from Poland. Most articles have been published from these countries.

We generated the geographical map of the author's countries/territories by using countries/territories co-citation results through Generate Google Earth Maps (KML 2.0) (Fig. 4b). The figure showed that countries/territories in the northern hemisphere participating in haze research were more than that in the southern hemisphere. On one hand, academic cooperative connections among countries/territories in the northern hemisphere were relatively concentrated; on the other hand, in recent years, the fact that some countries/territories including China, India, Russia, South Korea, and Belgium (Yang et al. 2015) have been facing severe air pollution

(a)

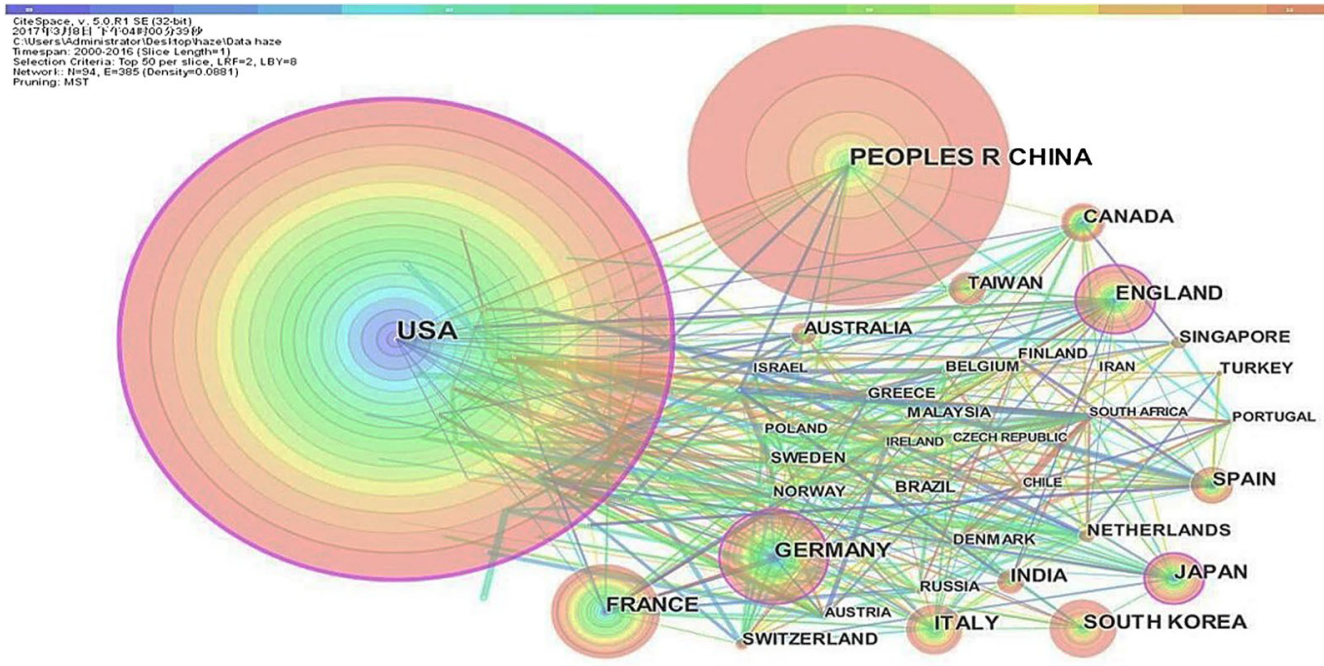

(b)

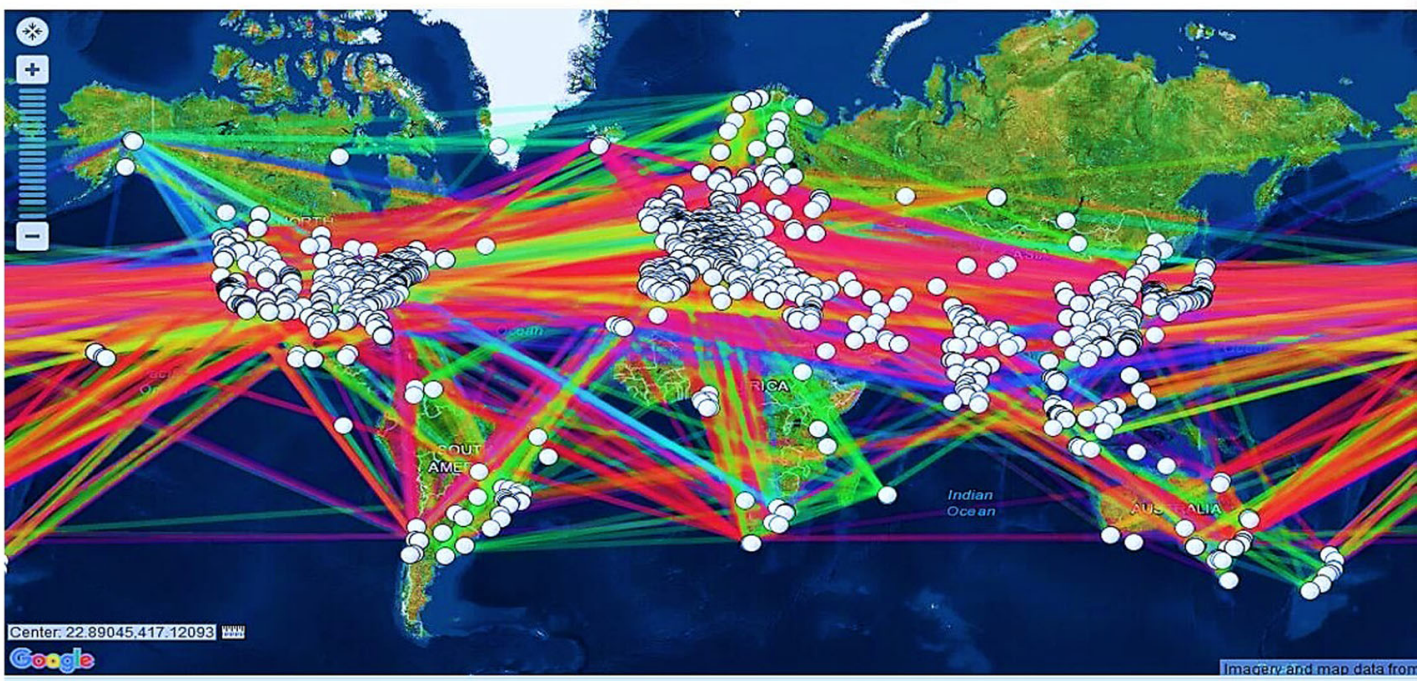

Fig. 4 a Country/territory co-citation map from 2000 to 2016. b Geographical map of countries/territory co-citation from 2000 to 2016 
Table 2 The top 30 most productive countries/territories

\begin{tabular}{llllll}
\hline Number & Frequency & $\begin{array}{l}\text { Country/ } \\
\text { territory }\end{array}$ & Number & Frequency & $\begin{array}{l}\text { Country/ } \\
\text { territory }\end{array}$ \\
\hline 1 & 1925 & USA & 16 & 95 & Singapore \\
2 & 1162 & $\begin{array}{l}\text { People's } \\
\text { Republic Of }\end{array}$ & 17 & 83 & Brazil \\
& \multicolumn{5}{c}{ China } \\
3 & 432 & Germany & 18 & 68 & Turkey \\
4 & 425 & France & 19 & 67 & Sweden \\
5 & 323 & England & 20 & 63 & Malaysia \\
6 & 297 & South Korea & 21 & 62 & Norway \\
7 & 268 & Italy & 22 & 61 & Russia \\
8 & 259 & Japan & 23 & 59 & Belgium \\
9 & 223 & Canada & 24 & 52 & Finland \\
10 & 197 & Spain & 25 & 52 & Denmark \\
11 & 179 & India & 26 & 49 & Greece \\
12 & 162 & Australia & 27 & 45 & Israel \\
13 & 158 & Taiwan & 28 & 43 & Austria \\
14 & 114 & Netherlands & 29 & 43 & Portugal \\
15 & 108 & Switzerland & 30 & 38 & Poland \\
\hline
\end{tabular}

problem indirectly reflected that air quality in the northern hemisphere was worse than that in the southern hemisphere. As a result, scholars in the northern hemisphere took close attention to study air pollution problem including the haze phenomenon.

\section{Institutions}

The academic cooperative connections among institutes generating research on haze are shown in Fig. 5a. The top 30 most productive institutes for total publications are shown in Table 3.The major academic contributions, which were concluded in terms of total publication frequency, primarily originated from the Chinese Acad Sci, NASA, CALTECH, and Univ Arizona. As to the publication distribution of the top 30 most productive institutes, 347 are from the Chinese Acad Sci, followed by 233 from NASA (National Aeronautics and Space Administration), 154 from CALTECH (California Institute of Technology), 122 from Univ Arizona, 96 from Univ Maryland, 95 from Peking Univ, 76 from Univ Chinese Acad Sci, 74 from Nanjing Univ Informat Sci \& Technol, 69 from Univ Colorado, 69 from Tsinghua Univ, 66 from Univ Paris 06, 66 from Fudan Univ, 59 from Univ Calif Berkeley, 55 from Natl Univ Singapore, 54 from Chinese Acad Meteorol Sci, 54 from Observ Paris, 53 from Cornell Univ, 50 from Univ Oxford, 50 from China Meteorol Adm, 49 from Johns Hopkins Univ, 49 from Beijing Normal Univ, 43 from Univ Calif Santa Cruz, 40 from NOAA(National Oceanic and Atmospheric Administration), 39 from Chinese Res Inst Environm Sci, 37 from Colorado
State Univ, 35 from Univ Wisconsin, 32 from Harvard Univ, 31 from CSIC(Spanish National Research Council), 30 from Nanjing Univ, and 30 from CNRS (Centre National De La Recherche Scientifique).

Among the top 30 institutes, 14 are in the USA, 11 are in China, three are in France, and one each in Singapore and Spain. In the USA, the number of publications, NASA is top ranked; in China, Chinese Acad Sci is top ranked. Result shows that higher education institutes are a remarkable backbone of scientific research (Table 3).

\section{Keywords}

We can comprehend an understanding of the development of research topic through the keywords of an article (Chen et al. 2015). According to the annual snapshotsa developmental time zone of haze research is shown in Fig. 5b. Each keyword node is represented as tree rings and the rings and links are represented in a spectrum of colors corresponding to the years of the keywords' appearance (Chen 2014). The major focuses of haze research evolved from 2000 to 2016. For example, scholars emphasized research on haze by using photorefractive keratectomy in situ keratomileusis and excimer laser in 2001 whereas in 2006 studies published mainly focused on haze formation air pollution and chemical composition. Besides, no new hot topics of research emerged in 2010 .

Of all the words shown in Table 4, "haze," with a frequency of 1088 in the network, and variants including "aerosol" (474), "atmosphere" (407), and "model" (306), are high-frequency keywords. The keywords "optical property" (294), "particle" (203), "emission" (194),"surface" (187), "pollution" (165), "PM 2.5 " (144), "visibility" (136), "chemistry" (125), "particulate matter" (120), "haze formation" (120), "temperature" (118), “PM 25 " (105), "air quality" (104), "impact" (100), "climate" (94), "source apportionment" (93) and "stability" (91), represent the contents of the haze research, such as formation, features and controlling strategies of haze; "China" (177) represents the study area of haze research; "model" (306), "photorefractive keratectomy" (290), "in situ keratomileusis" (255), "TITAN (Texas Instruments test analyzer)" (200), "excimer laser" (127), "myopia" (107), and "film" (100) represent the methods of haze research.

\section{Conclusions}

Because of causing serious air quality problems, haze is an important research object to attract scholars' attentions all over the world. The last decade has witnessed rapid development in the literature on haze; however, there have been few attempts to map the global research through the bibliometric approach. Therefore, understanding the research evolution and 
(a)

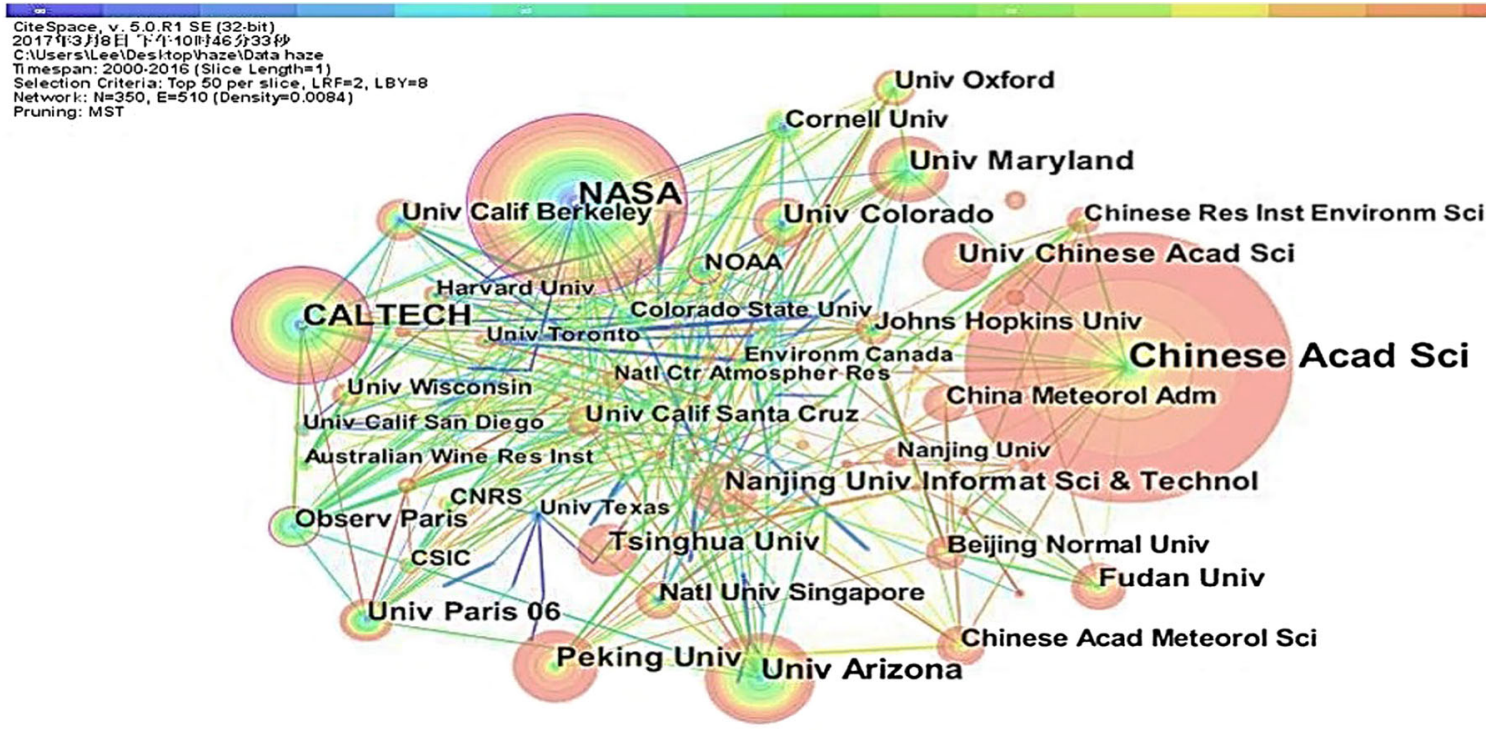

(b)

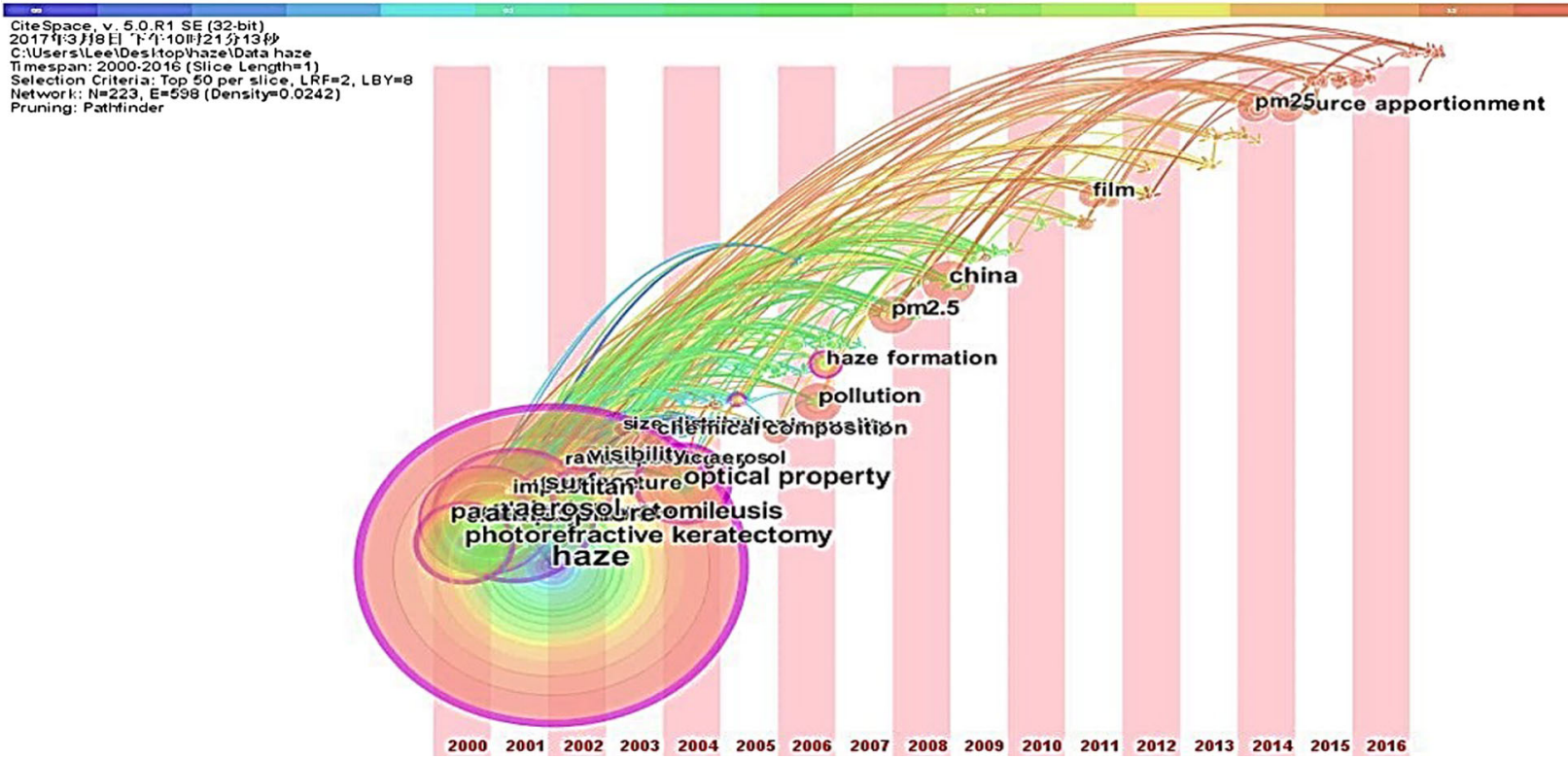

Fig. 5 (a) Institute co-citation map from 2000 to 2016 (b) Time zone view of the keywords co-citation map from 2000 to 2016

orientation in haze analysis becomes a pivotal goal for related researchers, countries/territories, and institutes. Based on 5604 documents on haze in the Science Citation Index Expanded (SCI-Expanded) and Social Science Citation Index (SSCI) of the ISI-Thomson Reuters Scientific database, research network patterns and hotspots about haze research were generated from 2000 to 2016 . From the present study status, research on haze will continue to growth rapidly. According to the data from SCI-Expanded and SSCI database, the top five most productive authors, of which were Li J. with 46 articles, Li L. with 29, Zhang Y. with 29, Wang Y. with 29, Zhang Q. with 27, and Cao J.J. with 26, as well as other scholars in this domain, have made great contributions to haze research. The publications on haze research were primarily originated from the USA, China, Germany, and France. The dominant hot spots of haze research could be concluded as "aerosol," "atmosphere," "particle," "PM $\mathrm{PM}_{2.5}$ " and "air quality" from 2000 to 2016 . And these will still be the key issues in haze research in the future. All of these research findings could provide foundation to understand the research developing process and trends in haze analysis for researchers in the field of haze.

Yang et al. (2015) first examined publication share, growth rate, and top journals of research on haze by using scientometrics approach. However, the method of the paper is only statistical analysis and the study area is constrained within China. Therefore, there is still short of a historical and detailed evolution of haze research within the world. 
Table 3 The top 30 most productive institutes

\begin{tabular}{llllll}
\hline Number & Frequency & Institutes & Number & Frequency & Institutes \\
\hline 1 & 347 & Chinese Acad Sci & 16 & 54 & Observ Paris \\
2 & 233 & NASA & 17 & 53 & Cornell Univ \\
3 & 154 & CALTECH & 18 & 50 & Univ Oxford \\
4 & 122 & Univ Arizona & 19 & 50 & China Meteorol Adm \\
5 & 96 & Univ Maryland & 20 & 49 & Johns Hopkins Univ \\
6 & 95 & Peking Univ & 21 & 49 & Beijing Normal Univ \\
7 & 76 & Univ Chinese Acad Sci & 22 & 43 & Univ Calif Santa Cruz \\
8 & 74 & Nanjing Univ Informat Sci \& Technol & 23 & 40 & NOAA \\
9 & 69 & Univ Colorado & 24 & 39 & Chinese Res Inst Environm Sci \\
10 & 69 & Tsinghua Univ & 25 & 37 & Colorado State Univ \\
11 & 66 & Univ Paris 06 & 26 & 35 & Univ Wisconsin \\
12 & 66 & Fudan Univ & 27 & 32 & Harvard Univ \\
13 & 59 & Univ Calif Berkeley & 28 & 31 & CSIC \\
14 & 55 & Natl Univ Singapore & 29 & 30 & Nanjing Univ \\
15 & 54 & Chinese Acad Meteorol Sci & 30 & 30 & CNRS \\
\hline
\end{tabular}

This is the first comprehensive quantitative and qualitative bibliometric analysis of scientific documents in the field of haze research. The research findings, related to distribution of authors, institutes, countries/ territories, and keywords have been visually shown by using CiteSpace, identified the development trends or future research orientations. In addition, to provide evidence of combination between bibliometric analysis and geographical analysis, the geographical map of the author's countries/territories was generated by using bibliometric results through Generate Google Earth Maps.
Bibliometric tools, including CiteSpace, Netdraw, VOSviewer, and HistCite, provide a comprehensive approach to identify the development trends or future research orientations by analyzing the publication output, keywords, authors, institutes, and countries/territories. Those analysis results related to one research field can not only provide references for scholars, but also help policy makers to recognize and evaluate the advanced international research organizations.

Based on the above analysis and discussion, the future studies should focus on the following aspects: (1) use various

Table 4 The top 30 most productive keywords

\begin{tabular}{|c|c|c|c|c|c|}
\hline Number & Frequency & Keyword & Number & Frequency & Keyword \\
\hline 1 & 1088 & Haze & 16 & 136 & Visibility \\
\hline 2 & 474 & Aerosol & 17 & 127 & Excimer laser \\
\hline 3 & 407 & Atmosphere & 18 & 125 & Chemistry \\
\hline 4 & 306 & Model & 19 & 123 & Chemical composition \\
\hline 5 & 296 & Air pollution & 20 & 120 & Particulate matter \\
\hline 6 & 294 & Optical property & 21 & 120 & Haze formation \\
\hline 7 & 290 & Photorefractive keratectomy & 22 & 118 & Temperature \\
\hline 8 & 255 & In situ keratomileusis & 23 & 107 & Myopia \\
\hline 9 & 203 & Particle & 24 & 105 & $\mathrm{PM}_{25}$ \\
\hline 10 & 200 & TITAN & 25 & 104 & Air quality \\
\hline 11 & 194 & Emission & 26 & 100 & Impact \\
\hline 12 & 187 & Surface & 27 & 100 & Film \\
\hline 13 & 177 & China & 28 & 94 & Climate \\
\hline 14 & 165 & Pollution & 29 & 93 & Source apportionment \\
\hline 15 & 144 & $\mathrm{PM}_{2.5}$ & 30 & 91 & Stability \\
\hline
\end{tabular}


bibliometric tools to compare the current bibliometric approaches; (2) explore a suitable way to fully develop combination between bibliometric analysis and geographical analysis.

Funding information This study has been supported by the National Natural Science Foundation of China (41371226), National Key Technology Support Program (2015BAD06B01) and Beijing Municipal Science and Technology Project (Z161100001116016).

\section{Compliance with ethical standards}

Conflict of interest The authors declare that there is no conflict of interest.

\section{References}

Abramo G, D'Angelo CA, Viel F (2011) The field-standardized average impact of national research systems compared to world average: the case of Italy. Scientometrics 88(2):599-615

Bajwa RS, Yaldram K (2013) Bibliometric analysis of biotechnology research in Pakistan. Scientometrics 95:529-540

Bates DV, Sizto R (1987) Air pollution and hospital admissions in Southern Ontario: the acid summer haze effect. Environ Res 43: 317-331

Bytnerowicz A, Padgett PE, Arbaugh MJ (2003) Methodological needs and perspectives for monitoring ambient air pollution and regional haze: tools for understanding forest responses. Dev Environ Sci 2: 263-283

Chen C (2004) Searching for intellectual turning points: progressive knowledge domain visualization. Proc Natl Acad Sci U S A 101(Suppl. 1):5303-5310

Chen C (2006) CiteSpace II: detecting and visualizing emerging trends and transient patterns in scientific literature. J Am Soc Inform Sci Technol 57(3):359-377

Chen C (2014) The CiteSpace manual. Retrieved from http://cluster. ischool.drexel.edu/ cchen/citespace/CiteSpaceManual.pdf. Accessed 20 August 2016

Chen H, Hu D, Wang L, Mellouki A, Chen J (2015) Modification in light absorption cross section of laboratory generated black carbon-brown carbon particles upon surface reaction and hydration. Atmos Environ 116:253-261

Chen D, Liu Z, Luo Z, Webber M, Chen J (2016) Bibliometric and visualized analysis of emergy research. Ecol Eng 90:285-293

Davies SJ, Unam L (1999) Smoke-haze from the 1997 Indonesian forest fires: effects on pollution levels, local climate, atmospheric $\mathrm{CO} 2$ concentrations, and tree photosynthesis. Forest Ecol Manag 124(2-3):137-144

Davis DL, Bell ML, Fletcher T (2002) A look back at the London smog of 1952 and the half century since. Environ Health Perspect 110(12): A734-A735

Fu HB, Chen JM (2017) Formation, features and controlling strategies of severe haze-fog pollutions in China. Sci Total Environ 578:121-138

Gao G (2008) The climatic characteristics and change of haze days over China during 1961-2005. Acta Geograph Sin 63(7):761-768

Gao JH, Woodward A, Vardoulakis S, Kovats S, Wilkinson P, Li LP, Xu L, Li J, Yang J, Li J, Cao LN, Liu XB, Wu HX, Liu QY (2017) Haze, public health and mitigation measures in China: a review of the current evidence for further policy response. Sci Total Environ 578:148-157
Guo S, Hu M, Zamora ML, Peng JF, Shang DJ, Zheng J, Du ZF, Wu ZJ, Shao M, Zeng LM, Molina MJ, Zhang RY (2014) Elucidating severe urban haze formation in China. Proc Natl Acad Sci U S A 111(49): 17373-17378

Gupta BM, Bala A (2012) S\&T publications output of Nepal: a quantitative analysis, 2001-10. Scientometrics 93:1029-1046

Hand JL, Schichtel BA, Malm WC (2014) Widespread reductions in haze across the United States from the early 1990s through 2011. Atmos Environ 94:671-679

Jansen RC, Shi Y, Chen JM, Hu YJ, Xu C, Hong SM, Li J, Zhang M (2014) Using hourly measurements to explore the role of secondary inorganic aerosol in PM2.5 during haze and fog in Hangzhou, China. Adv Atmos Sci 31:1427-1434

Kim Oanh NT, Leelasakultum K (2011) Analysis of meteorology and emission in haze episode prevalence over mountain-bounded region for early warning. Sci Total Environ 409(11):2261-2271

Kulmala M (2015) China's choking cocktail. Nature 526:497-499

Li W, Zhao Y (2015) Bibliometric analysis of global environmental assessment research in a 20-year period. Environ Impact Assess Rev 50:158-166

Li J, Jovanovic A, Klimek P, Guo XH (2015) Bibliometric analysis of fracking scientific literature. Scientometrics 105:1273

Li C, Wu K, Wu J (2017) Urban land use change and its socio-economic driving forces in China: a case study in Beijing, Tianjin and Hebei region. Environ Dev Sustain. https://doi.org/10.1007/s10668-0179928-6

Liu Y, Li Y, Chen C (2015) Pollution: build on success in China. Nature 517:145

Ma JZ, Xu XB, Zhao CS, Yan P (2012) A review of atmospheric chemistry research in China: photochemical smog, haze pollution, and gas-aerosol interactions. Adv Atmos Sci 29:1006-1026

Matthews AP (2013) Physics publication productivity in South African universities. Scientometrics 95:69-86

Mayr P, Scharnhorst A (2014) Scientometrics and information retrieval: weak-links revitalized. Scientometrics 102:2193-2199

Ren J, Li B, Yu D, Liu J, Ma Z (2016) Approaches to prevent the patients with chronic airway diseases from exacerbation in the haze weather. J Thorac Dis 8:E1-E7

Sun Y, Wang Z, Du W, Zhang Q (2015) Long-term real-time measurements of aerosol particle composition in Beijing, China: seasonal variations, meteorological effects, and source analysis. Atmos Chem Phys 15:10149-10165

Thurston GD, Iot K, Hayes CG, Bates DV, Lippmann M (1994) Respiratory hospital admissions and summertime haze air pollution in Toronto, Ontario: consideration of the role of acid aerosols. Environ Res 65:271-290

Tie X, Wu D, Brasseur G (2009) Lung cancer mortality and exposure to atmospheric aerosol particles in Guangzhou, China. Atmos Environ 43:2375-2377

Tonnesen G, Wang Z, Omary M, Chien C (2003) Formulation and application of regional air quality modeling for integrated assessments of urban and wildland pollution. Dev Environ Sci 2(02):299-324

Voiland A (2010) New map offers a global view of health-sapping air pollution. Air Quality and Climate Change 44(4): EI-14-EI-14

Wang W, Zheng G (2013) Green paper on climate change: a report on fighting climate change 2013. Social Sciences Academic Press, pp. 184-186

Wang MH, Yu TC, Ho YS (2010) A bibliometric analysis of the performance of water research. Scientometrics 84(3):813-820

Wang X, Liu T, Bernard F, Ding X, Wen S, Zhang Y, Zhang Z, He Q, Lü S, Chen J, Saunders S, Yu J (2014) Design and characterization of a smog chamber for studying gas-phase chemical mechanisms and aerosol formation. Atmos Meas Tech 7:301-313

Wu XH, Chen YF, Guo J, Wang GZ, Gong YM (2017) Spatial concentration, impact factors and prevention control measures of PM2.5 pollution in China. Nat Hazards 86:393-410 
Yang L, Han LZ, Chen ZL, Zhou JB, Wang J (2015) Growing trend of China's contribution to haze research. Scientometrics 105(1):1-11

Zhang ZY, Gong DY, Kim SJ, Mao R, Xu J, Zhao XJ, Ma ZQ (2015a) Cause and predictability for the severe haze pollutions in downtown Beijing during November-December. Sci Total Environ (in press). https://doi.org/10.1016/j.scitotenv.2016.12.070

Zhang W, Shen ZX, Cao JJ, Zhang RJ, Zhang LM, Huang RJ, Zheng CJ, Wang LQ, Liu SX, Xu HM, Zheng CL, Liu PP (2015b) Variations in $\mathrm{PM} 2.5$, TSP, $\mathrm{BC}$, and trace gases $\left(\mathrm{NO}_{2}, \mathrm{SO}_{2}\right.$, and $\left.\mathrm{O}_{3}\right)$ between haze and non-haze episodes in winter over Xi' an,China. Atmos Environ 112:64-71

Zhang L, Wang T, Lv M, Zhang Q (2015c) On the severe haze in Beijing during January 2013: unraveling the effects of meteorological anomalies with WRF-Chem. Atmos Environ 104:11-21

Zhang XY, Wang L, Wang WH, Cao DJ, Wang X, Ye DX (2015d) Longterm trend and spatiotemporal variations of haze over China by satellite observations from 1979 to 2013. Atmos Environ 119:362373 